\title{
The physician's gender influences the results of the diagnostic workup for erectile dysfunction
}

\author{
Giulia Rastrelli $^{1}$ | Sarah Cipriani ${ }^{1}$ | Andrea Craparo ${ }^{2,3}$ | Sara De Vincentis ${ }^{2,3}$ | \\ Antonio R. M. Granata ${ }^{3}$ | Giorgia Spaggiari ${ }^{3}$ | Manuela Simoni ${ }^{2,3}$ | Mario Maggi ${ }^{1}$ \\ Daniele Santi ${ }^{2,3}$
}

\author{
${ }^{1}$ Sexual Medicine and Andrology Unit, \\ Department of Experimental Clinical and \\ Biomedical Sciences 'Mario Serio', University \\ of Florence, Florence, Italy \\ ${ }^{2}$ Unit of Endocrinology, Department of \\ Biomedical, Metabolic and Neural Sciences, \\ University of Modena and Reggio Emilia, \\ Modena, Italy \\ ${ }^{3}$ Unit of Endocrinology, Department of \\ Medical Specialties, Azienda Ospedaliero- \\ Universitaria of Modena, Modena, Italy \\ Correspondence \\ Daniele Santi, Unit of Endocrinology, \\ OCSAE, Via P. Giardini 1355, 41126, \\ Modena, Italy. \\ Email: daniele.santi@unimore.it \\ Funding information \\ This research did not receive any specific \\ grant from any funding agency in the public, \\ commercial or not-for-profit sector.
}

\begin{abstract}
Background: Despite the well-known influence of psychological and situational factors on erectile dysfunction, the influence of the physician's gender on the andrological workup has never been investigated so far.

Objectives: To investigate physician's gender influence on the erectile dysfunction diagnostic workup.

Materials and methods: Cross-sectional study with retrospective data collection. We evaluate a consecutive series of erectile dysfunction patients: 95 at the University of Modena and Reggio Emilia (UNIMORE) and 1808 at the University of Florence (UNIFI). In the UNIMORE cohort (Cohort 1), intracavernousal injection test was performed in case of suspected vascular pathogenic component. In the UNIFI cohort (Cohort 2), patients were evaluated by structured interview on erectile dysfunction and ANDROTEST. Both cohorts were divided into two groups according to the gender of the physician who performed the intracavernousal injection test or the structured interview.

Results: In Cohort 1, patients who had the intracavernousal injection test performed by a female physician had a significantly higher probability of obtaining a better intracavernousal injection test response. In Cohort 2, patients interviewed by female physician more frequently reported to have a conflictual couple relationship and a reduced frequency of climax in their partners. However, they reported less difficulties in achieving and maintaining erection, higher frequency of autoeroticism, lower occurrence of erectile dysfunction during masturbation and lower impairment in morning erections.

Conclusions: Physician's gender affects the results obtained during the erectile dysfunction diagnostic workup. Men interviewed by a female physician describe a less severe erectile dysfunction probably as attempt to defend their own virility. On the other hand, the presence of a male physician during intracavernousal injection test is associated to a worse response suggesting a possible unconscious competition.
\end{abstract}

\section{KEYWORDS}

erectile dysfunction, Physician gender, intracavernousal injection, structured interview of erectile function 


\section{1 | INTRODUCTION}

Erectile dysfunction (ED) is a very common symptom affecting 15\%$25 \%$ of men in the general population and achieving a prevalence of up to $70 \%$ in elderly men. ${ }^{1}$ Despite its widespread distribution and its great impact on the quality of men' and couple's life, ${ }^{2}$ it is estimated that only $30 \%$ of men with ED consult a physician for this problem. ${ }^{3}$ Several reasons could explain this low consultation rate. Among these, embarrassment certainly plays an important role. The cross-national survey on Male Health Issues-involving about 3000 men aged 20-75 years with current or former ED from US and five European countries, including Italy-has shown that more than $30 \%$ of participants find impossible to talk about ED face to face with someone and up to $40 \%$ think that would not feel comfortable to share this symptom even with a doctor. ${ }^{4}$

In this context, the doctor-patient relationship is pivotal and physicians should be very cautious in establishing a good dialogue, which allows investigating sexual problems, thus providing the opportunity either to have more insight in patient's general health or to improve his quality of life. ${ }^{5,6}$ Indeed, specific knowledge on sexual medicine is a valuable competence and communication skills are crucial. Several personal characteristics may modulate the communicating approach, and gender can be easily hypothesized as one of these.

The differences in clinical practice according to the physician's gender have been previously evaluated in a limited number of medical settings, mostly among general practitioners and internal medicine. A meta-analysis of the results of 29 observational studies dealing with the communication styles of male and female physicians during visits ${ }^{6}$ has shown that females engage slightly longer visits. During these, females are more prone to favor active involvement of patients and to assume a less dominating stance toward them, creating, more often than their male colleagues, a positive talk with encouraging and reassuring attitudes. ${ }^{6}$ Although the studies report quite subtle differences in male and female physician styles during visit, they seem to translate into a greater patients' satisfaction for visit performed by female physicians. ${ }^{6}$ Accordingly, issues addressed during visits in a sexual medicine setting are very sensitive and it is obvious to assume that patients would be more comfortable in talking with a physician of the same gender. However, it could be also hypothesized that sharing a sexual problem with a person of the same sex, albeit a doctor, could result in feeling judged or compared, rather than understood or helped. Conversely, a person of the opposite gender could be perceived as more objective and sympathetic. The differences in visits performed by male or female physicians in sexual medicine setting have never been studied so far. Hence, we performed a cross-sectional clinical study aimed at evaluating the differences during a visit for ED-either in referring the problem or in diagnostic tests-categorizing information according to the gender of physician who performed the visit. The study was conceived after the empirical observation at the Andrology Unit of the University of Modena and Reggio Emilia (UNIMORE) that female physicians-despite standardized procedures and equal training of their male counterpart-usually obtain better results at the intracavernousal injection $(\mathrm{ICI})$ test.

\section{2 | MATERIALS AND METHODS}

This is a cross-sectional study performed by a retrospective review of clinical data in two different cohorts of patients consulting for sexual dysfunction in two Italian Andrology centers. The study was conceived after the empirical observation at the Andrology Unit of the University of Modena and Reggio Emilia (UNIMORE) that female physicians-despite standardized procedures and equal training of their male counterpart-usually obtain better results at the intracavernousal injection (ICI) test. The Sexual Medicine and Andrology Unit of the University of Florence (UNIFI) was involved because the standard clinical practice for the initial assessment of ED patients relies on structured interviews, which are equally performed by male and female physicians. At the UNIFI, the ICl testing and the penile color Doppler ultrasound (PDCU) are part of the routine clinical practice but only male physicians perform these two clinical procedures. The UNIFI was involved to verify whether the differences according to physician gender obtained at the UNIMORE in the evaluation of ED patients are consistent with those derived from a detailed and standardized evaluation of the characteristics of ED, the presence of other sexual symptoms and the assessment of relational and psychological issues possibly affecting sexual function. Hence, the use of two cohorts allowed for the collection of complementary information useful for evaluating different aspects of male sexual health, as derived from either subjective referral of a clinical problem or a widespread diagnostic procedure generally deemed as objective.

\section{1 | UNIMORE cohort (Cohort 1)}

A consecutive series of patients $(n=95)$ consulting in the 2018 the Andrology Unit of UNIMORE for ED were retrospectively evaluated. Routinely, each patient was evaluated using a standard diagnostic workup (Figure 1). Initially, the patient's medical history was collected with an unstructured interview, including information on age, smoking status, comorbid medical and psychological conditions, prior surgery, current medications, and family history of cardiovascular (CV) disease. ${ }^{5}$ Moreover, ED was thoroughly investigated considering its onset period and modality, its severity, possible situational factors, the presence/absence of morning erections, the presence/absence of masturbatory erections and the prior use of pro-erectogenic therapies. ED severity was quantified using the International Index of Erectile Function (IIEF)5. ${ }^{7}$ Alongside medical history, when a vascular pathogenic component was suspected, blood drawn for biochemical assessment and an $\mathrm{ICl}$ test with vasoactive agents was recommended. $\mathrm{ICI}$ test was proposed to patients aged over 50 years in the absence of 
FIGURE 1 Diagnostic protocols routinely applied at UNIMORE and UNIFI

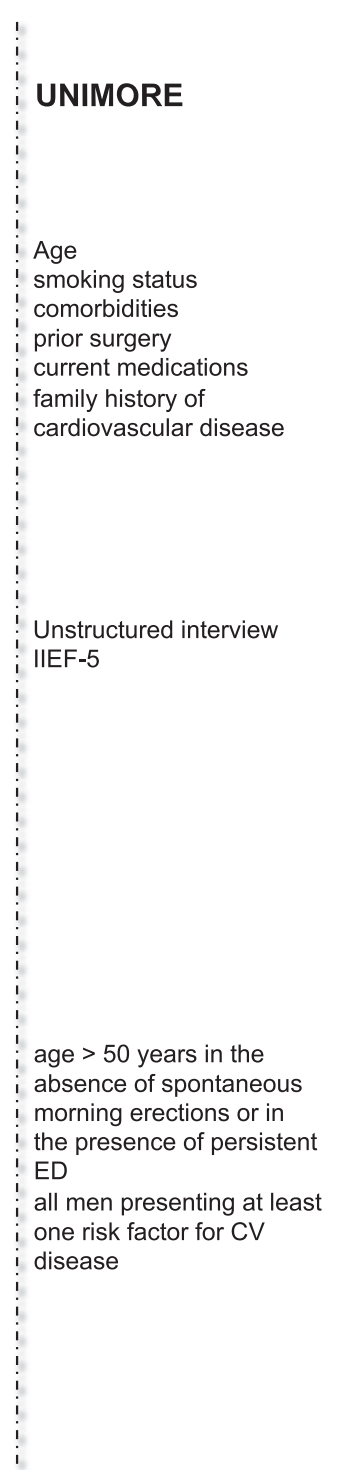

Erectile dysfunction (ED) diagnostic workup performed at both Units

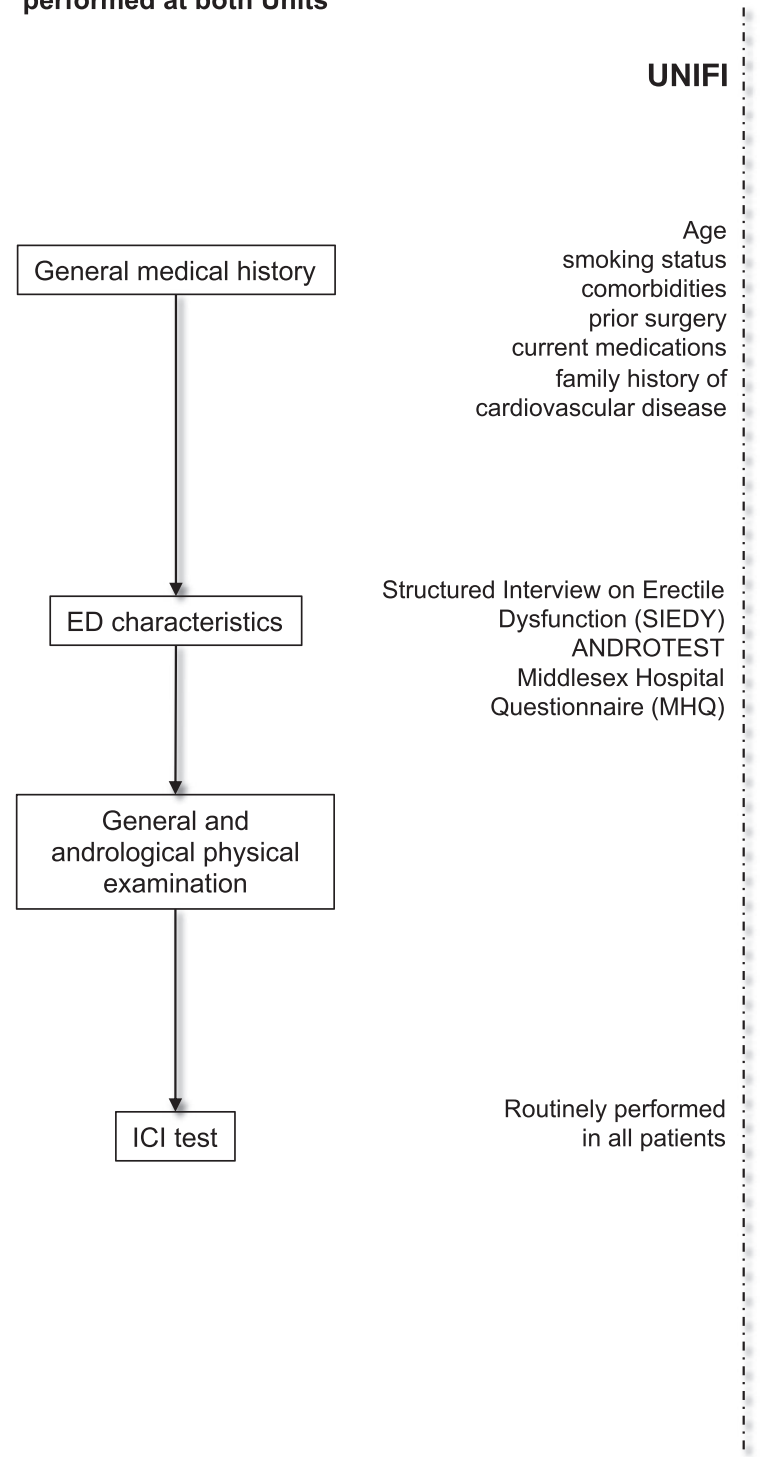

spontaneous morning erections or in the presence of persistent $\mathrm{ED}$, and to all men presenting at least one risk factor for CV disease, such as diabetes mellitus, hypertension, dyslipidemia, or previous CV event, irrespective of age. The ICI test for ED is a minimally invasive procedure contemplating the injection of 5 or $10 \mu \mathrm{g}$ of prostaglandin E1 (PGE1) in a corpus cavernosum penis. ${ }^{8}$ After 10 minutes from the injection, the drug-induced erection was assessed using a buckling device, that is, a standard weight scale connected to a plastic cap with a ventral surface concavity (Rigid test ${ }^{\circledR}$, Androline srl - Milano, Italy). A full erection was depicted in case of an absent penile buckling when a $1000 \mathrm{~g}$ downward force was slowly applied to the glans, following the erect shaft axis.? Moreover, in order to assess the gradual nature of the response, we arbitrarily divided patients into four groups according to the buckling test graduation: (I) absent $<500 \mathrm{~g}$, (II) mild 500-750 g, (III) moderate 750-1000 g, and (IV) optimal response $>1000 \mathrm{~g}$. In the UNIMORE center, this procedure was indiscriminately performed by two male or by two female physicians. According to the gender of the physician who performed the $\mathrm{ICl}$ test, patients were further subdivided in group $1 \mathrm{a}$ (male practitioners) and group $1 \mathrm{~b}$ (female practitioners).

\subsection{UNIFI cohort (Cohort 2)}

A consecutive series of 1808 patients consulting the Sexual Medicine and Andrology Unit of the UNIFI for ED were studied. Each patient underwent a standard diagnostic protocol (Figure 1) and signed an informed consent for collecting clinical data. At the beginning of the diagnostic workup, all patients were interviewed using the Structured Interview on Erectile Dysfunction (SIEDY) and ANDROTEST in the absence of their partners, administered by male or female physician. SIEDY is a validated 13-item structured interview evaluating the pathogenic components of ED (organic, relational, or intrapsychic) ${ }^{10}$ whereas ANDROTEST is a validated 12-item structured interview for the screening of hypogonadism in 
patients with sexual dysfunction. ${ }^{11}$ For both interviews, answers to each question are arranged on a Likert scale. For the purpose of the present study, the answers have been transformed into dummy variables. All patients were also asked to report all their comorbidities and drugs used. All patients underwent a complete physical and biochemical examination. Blood samples were drawn in the morning, after an overnight fast, for the determination of lipid profile, glucose, and total testosterone. The 10 -year risk was estimated by the Progetto Cuore algorithm, ${ }^{12}$ demonstrated as a proper algorithm also for men with sexual dysfunction. ${ }^{13}$ Penile blood flows were measured by PDCU before and 20 minutes after an intracavernosal injection of $10 \mu \mathrm{g}$ of PGE1 (dynamic evaluation. Twenty minutes after the injection, the erectile response was assessed by a palpation and recorded on a four-point scale: $1=$ no response, 2 = rigidity, insufficient for intercourse $(<50 \%) ; 3=$ rigidity, sufficient for intercourse ( $>50 \%$ ); 4 = full erection $(>90 \%)$. Both the $\mathrm{ICl}$ test and the PDCU were performed in the UNIFI center by male physicians. The Middlesex Hospital Questionnaire (MHQ), ${ }^{14}$ a brief self-reported questionnaire for the screening of the symptoms of mental disorders in non-psychiatric settings, was administered to each patient in order to quantify the psychological symptoms. According to the gender of the physician who performed the sexual interview, patients were divided into group $2 a$ (male) and group $2 \mathrm{~b}$ (female).

\section{3 | Statistical analysis}

Data are reported as mean \pm standard deviation when normally distributed and as median interquartile range] when non-normally distributed. Comparisons between groups have been performed by Student's $t$ test and chi-square test for continuous and categorical parameters, respectively. For non-normal distributed parameters, the Student's $t$ test was performed after the logarithmic $\left(\log _{10}\right)$ transformation of the variable, which allowed the achievement of normality. Binary and ordinal logistic regressions have been used for evaluating the unadjusted and adjusted associations between variables, when the dependent parameter was binary or categorical, respectively. Results from binary or ordinal logistic regressions were reported as odds ratio (OR) along with their 95\% confidence interval (Cl).

All the statistical analyses were performed by Stata MP 13.1 for Windows (StataCorp, College Station, TX, USA), and $P$ values $<0.05$ were considered statistically significant. All figures were produced using GraphPad Prism 5.02 (GraphPad Software, Inc, CA, USA).

\section{3 | RESULTS}

\section{1 | UNIMORE cohort (Cohort 1)}

The characteristics of the 95 men enrolled are reported in Table 1. Of these, 55 (57.9\%; group 1a) had the $\mathrm{ICI}$ test performed by a male physician, whereas in the remaining 40 (42.1\%; group 1 b), the $\mathrm{ICl}$ test was executed by a female physician. Group $1 \mathrm{a}$ and group $1 \mathrm{~b}$ did not differ in terms of age, education, testosterone levels, and CV risk factors (Table 1). In addition, men in group $1 \mathrm{a}$ and $1 \mathrm{~b}$ reported with a similar frequency to have a stable couple relationship and their partners' age was comparable (Table 1 ).

In men from group $1 \mathrm{~b}$, the severity of $\mathrm{ED}$, as assessed by the IIEF-5 score, and the duration of ED were not different from men in group 1a (Table 1). When evaluating the sexual symptoms associated with ED, as assessed in a previous visit by a different physician, it was found that group 1a and group $1 \mathrm{~b}$ had a similar prevalence of impairment in morning erections, ED during masturbation and reduced sexual desire (Table 1).

The $\mathrm{ICl}$ test response according to the gender of the physician who performed the test is reported in Figure 2. Men who had the test performed by a female physician (group 1b) had a significantly higher probability of obtaining a better ICI test response $(P=.012)$. This observation was confirmed even after excluding eight men who were tested with a higher dosage (10 or $20 \mu \mathrm{g}$ ) of $\mathrm{PGE}_{1}(\mathrm{OR}=2.92$ [1.30-6.55], $P=.009$ )

\section{2 | UNIFI cohort (Cohort 2)}

The characteristics of the 1808 men involved in the study are reported in Table 2. When comparing 857 men who were interviewed by a male (47.4\%; group 2a) or 951 interviewed by a female physician (52.6\%; group $2 b$ ), it was observed that men from group $2 b$ were slightly-although significantly-older, more educated and at higher CV risk, as assessed by the Progetto Cuore risk engine (Table 2). Group $2 \mathrm{a}$ and $2 \mathrm{~b}$ did not differ for prevalence of comorbidities, such as diabetes, previous CV events, hypertension, or psychiatric conditions (Table 2). In addition, there were no differences in total testosterone, glucose, and lipids levels (Table 2). The results from the self-administered questionnaire $\mathrm{MHQ}$ showed that men interviewed by male or female physicians scored similarly, not suggesting differences in psychiatric symptoms (Table 2). When considering the results from the $\mathrm{ICI}$ test and PDCU assessment, both performed by male physicians, men from group $2 \mathrm{a}$ and $2 \mathrm{~b}$ did not show any significant difference (Table 2).

Due to the aforementioned differences in age, education degree, and Progetto Cuore risk score, the following analyses were adjusted for these confounders along with smoking habit. When considering the questions of SIEDY, which investigate the couple relationship, men interviewed by female physicians more frequently reported to have a conflictual relationship with their partner (Figure 3). In addition, they more often perceive a reduced frequency of climax in their partner, despite no different perception in partner's sexual desire (Figure 3). Men interviewed by male or female physicians did not report differently on extramarital relationships (Figure 3).

Concerning the characteristics of ED and the concomitant sexual complaints (Figure 3), it was observed that men interviewed by a female physician (group 2 b) reported less often difficulties in achieving 
TABLE 1 Characteristics of the UNIMORE cohort

\begin{tabular}{|c|c|c|c|c|}
\hline & Overall $(n=95)$ & Group 1a $(n=55)$ & Group $1 b(n=40)$ & $P$ \\
\hline Age (years) & $55.8 \pm 10.0$ & $55.9 \pm 10.1$ & $55.5 \pm 9.9$ & .859 \\
\hline \multicolumn{5}{|l|}{ Education (\%) } \\
\hline Primary & 5.3 & 5.3 & 5.3 & \multirow[t]{4}{*}{.351} \\
\hline Secondary & 52.6 & 47.4 & 57.9 & \\
\hline Higher & 34.2 & 31.6 & 36.8 & \\
\hline University & 7.9 & 15.8 & 0.0 & \\
\hline Current smoker (\%) & 18.9 & 16.4 & 22.5 & .451 \\
\hline Hypertension (\%) & 47.4 & 50.9 & 42.5 & .418 \\
\hline $\begin{array}{l}\text { Diabetes mellitus } \\
(\%)\end{array}$ & 27.7 & 31.5 & 22.5 & .336 \\
\hline Dyslipidemia (\%) & 29.5 & 29.1 & 30.0 & .924 \\
\hline $\begin{array}{c}\text { Cardiovascular } \\
\text { diseases (\%) }\end{array}$ & 16.8 & 18.2 & 15.0 & .682 \\
\hline $\begin{array}{l}\text { Stable couple } \\
\text { relationship (\%) }\end{array}$ & 93.7 & 92.7 & 95.0 & .653 \\
\hline Partner's age (years) & $49.9 \pm 10.1$ & $49.4 \pm 10.2$ & $50.6 \pm 10.1$ & .609 \\
\hline IIEF-5 score & $11.3 \pm 6.6$ & $11.7 \pm 6.6$ & $10.7 \pm 6.5$ & .520 \\
\hline $\begin{array}{l}\text { ED duration } \\
\text { (months) }\end{array}$ & $24.0[8.3-48.0]$ & $24.0[7.0-42.0]$ & $24.0[12.0-48.0]$ & $.221^{*}$ \\
\hline ED duration >2 y (\%) & 55.4 & 52.8 & 59.0 & .558 \\
\hline $\begin{array}{l}\text { ED during } \\
\text { masturbation (\%) }\end{array}$ & 54.7 & 54.5 & 55.0 & .965 \\
\hline $\begin{array}{l}\text { Impaired morning } \\
\text { erections (\%) }\end{array}$ & 57.4 & 51.9 & 65.0 & .202 \\
\hline $\begin{array}{l}\text { Decreased sexual } \\
\text { desire (\%) }\end{array}$ & 25.3 & 21.8 & 30.0 & .365 \\
\hline $\begin{array}{l}\text { Total testosterone } \\
(\mathrm{nmol} / \mathrm{L})\end{array}$ & $17.7 \pm 7.2$ & $17.4 \pm 6.9$ & $18.3 \pm 7.8$ & .576 \\
\hline \multicolumn{5}{|l|}{$\mathrm{PGE}_{1}$ dosage (\%) } \\
\hline $5 \mu \mathrm{g}$ & 91.6 & 92.7 & 90.0 & \multirow[t]{3}{*}{.228} \\
\hline $10 \mu \mathrm{g}$ & 6.3 & 3.6 & 10.0 & \\
\hline $20 \mu \mathrm{g}$ & 2.1 & 3.6 & 0.0 & \\
\hline
\end{tabular}

Note: Continuous variables are reported as mean \pm standard deviation when normally distributed or median [interquartile range] when non-normally distributed, categorical variables are reported as percentage. $P$ values refer to the comparison between group $1 \mathrm{a}$ (referent) and group $1 \mathrm{~b}$. Student's $t$ test and chi-square test were used for the comparison in continuous and categorical variables, respectively.

Abbreviations: IIEF-5, International Index on Erectile Function-5 items; ED, erectile dysfunction; $P E_{1}$, prostaglandin $E_{1}$.

${ }^{*} \log _{10}$ transformed values have been used for performing the $t$ test. and maintaining erection, as compared with those interviewed by a male physician (group 2a). Consistently, they reported a lower impairment in morning erections, a lower occurrence of erectile difficulties during masturbation, and a higher frequency of autoeroticism, despite admitting to feel guilt toward masturbation (Figure 3). No differences in frequency of sexual intercourse were found between men from group $2 a$ and $2 b$ (Figure 3). Men interviewed by a female physician (group $2 b$ ) complained more often about a decrease in sexual desire (Figure 3).

\section{4 | DISCUSSION}

In clinical practice, it is generally assumed that men complaining about sexual dysfunctions, in particular ED, prefer to interface with a male physician, probably to seek some sort of complicity in addressing a medical problem, which is considered embarrassing and may question their virility. Although routinely accepted, a clear demonstration of this phenomenon in an andrological setting has never been investigated with a scientific approach. 


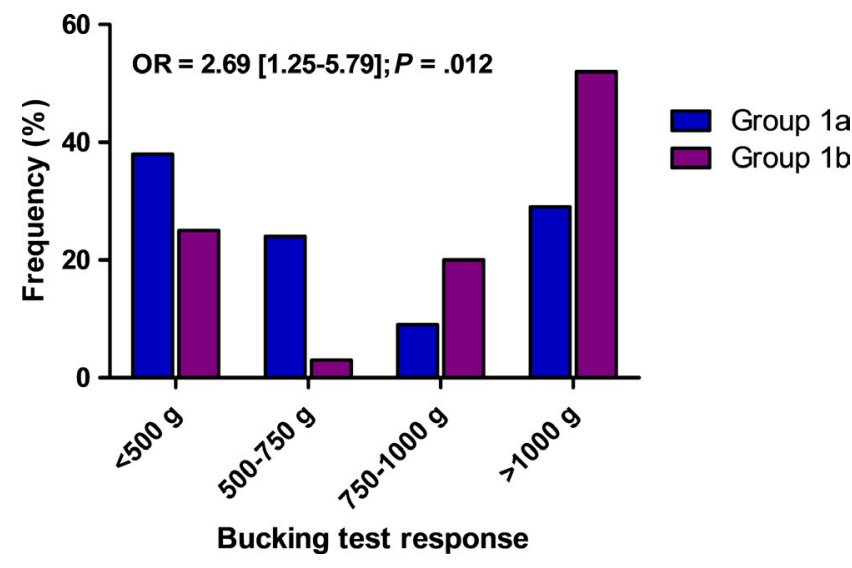

FIGURE 2 Buckling test response at ICI performed in the UNIMORE cohort according to the gender of the physician performing the test. The figure represents the intragroup frequency of buckling test response at ICI. Odds ratio (OR) derives from an ordinal logistic model using the physician gender as the independent variable (male as the referent) and the buckling test response as the dependent variable

In the present study, we found that patients interviewed by female physicians report more often a milder form of ED, during both sexual intercourse and masturbation, as well as a less frequent impairment in morning erections. The use of an objective measure of erectile function confirmed the findings from the structured in terview. In fact, men tested by female physicians have more than twofold higher probability of obtaining a better degree of erection upon the intracavernousal injection of $\mathrm{PGE}_{1}$. These differences do not have an organic basis because, in the UNIFI cohort, the ICI test and PDCU (performed at this center only by male physicians) yield similar results in men interviewed by males or females. On the other hand, at UNIMORE, the self-assessment of the erectile problem (IIEF-5 score) was similar in men tested with ICI by male or female physicians.

A possible explanation for the worse results captured by male physicians in the assessment of ED is the psychological uneasiness to share a breach in virility with another man who could be perceived as judgmental. This could result in a sort of performance anxiety with an increased sympathetic drive eventually leading to a worse $\mathrm{ICl}$ test result. The impact of anxiety on erectile function is a well-known phenomenon, which is observed in several clinical conditions. For instance, in the setting of couple infertility, several studies have shown that men are more prone to experience ED during their partner's fertile period, ${ }^{15}$ probably due to the psychological pressure of having sex aimed at conceiving a baby, ${ }^{16,17}$ which forces the intercourse around the women's ovulatory window. Men having sexual intercourse in conditions of limited privacy represent another example of the great influence of anxiety in sexual health. In a population of more than $\mathbf{3 7 0 0}$ men consulting for sexual dysfunction, having sex with limited privacy was associated with problems in maintaining the erection for the entire duration of the intercourse. ${ }^{18}$

Although the $\mathrm{ICl}$ test is used just to minimize the psychological component in inducing penile erection, the buckling test response after ICl could be evenly impaired by psychological components. This phenomenon is so much recognized that the so-called retesting has been suggested for minimizing the psychological effect in selected patients. ${ }^{19,20}$ Quite surprisingly, in the UNIMORE cohort, the test-related discomfort seems to be increased by the presence of a male physician. Conversely, the presence of a female physician may represent an element able to attenuate the negative impact of the psychological component in the ICl test or even a "motivation" to achieve a better response, satisfying the patient's need to display his virility.

The urge of patients to show themselves as a sort of "macho man" is confirmed by the replies to the structured interviews. In fact, when reporting on their partners, men are more prone to describe a strain relationship if interviewed by a female physician. In addition, they more frequently admit to a female physician that their partners have difficulties in achieving orgasm during the intercourse. These findings could be interpreted as a defense mechanism through which men lay the blame of ED on their partners in order to avoid admitting a flaw in their virility. Accordingly, patients interviewed by women report a decreased sexual desire despite a higher frequency of masturbation, suggesting that the reduction of sexual interest is specific to having sex with their partner rather than an overall impairment in sexual thoughts. Again, they seem to take the position of the innocent bystander even when disclosing a feeling of guilt toward autoeroticism, despite a stable frequency of masturbation.

Taken together, these results obtained in two independent cohorts of patients consulting for ED, show that, despite having homogenous characteristics when the assessment is independent of the staff gender (ie, PDCU, testosterone, glycolipid parameters, and MHQ in the UNIFI cohort; IIEF-5 score and testosterone in the UNIMORE cohort) or is scarcely sensitive to gender (ie, presence of comorbidities or CV risk factors), men have different behaviors according to the physician gender. In particular, the severity of erectile impairment is lower when captured by female physicians either when subjectively reported by patients or when objectively evaluated by the ICI test. This could reflect different phenomena. On one hand, it could confirm the stronger skills of female physician to put patients at ease,${ }^{21}$ which is reflected by better results at $\mathrm{ICI}$ test. On the other hand, it suggests the attitude of patients to stand up for their virility in front of women, thus minimizing their erectile difficulties while underlining the problems in the relationship.

A limitation of the present study is that the real conditions of the patients studied cannot be ascertained. In fact, it cannot be established whether men interviewed by female physicians really exaggerate the relational problem and minimize ED so that their virility is not questioned or whether they feel more comfortable in talking with a woman who is able to contextualize the sexual issue in a broader and more complete background. The results from the $\mathrm{ICl}$ test obtained at the UNIMORE tend to support the latter view, highlighting that the presence of a male physician is associated with a significantly worse $\mathrm{ICl}$ test response in otherwise comparable men. A further limitation is represented by the retrospective 
TABLE 2 Characteristics of the UNIFI cohort

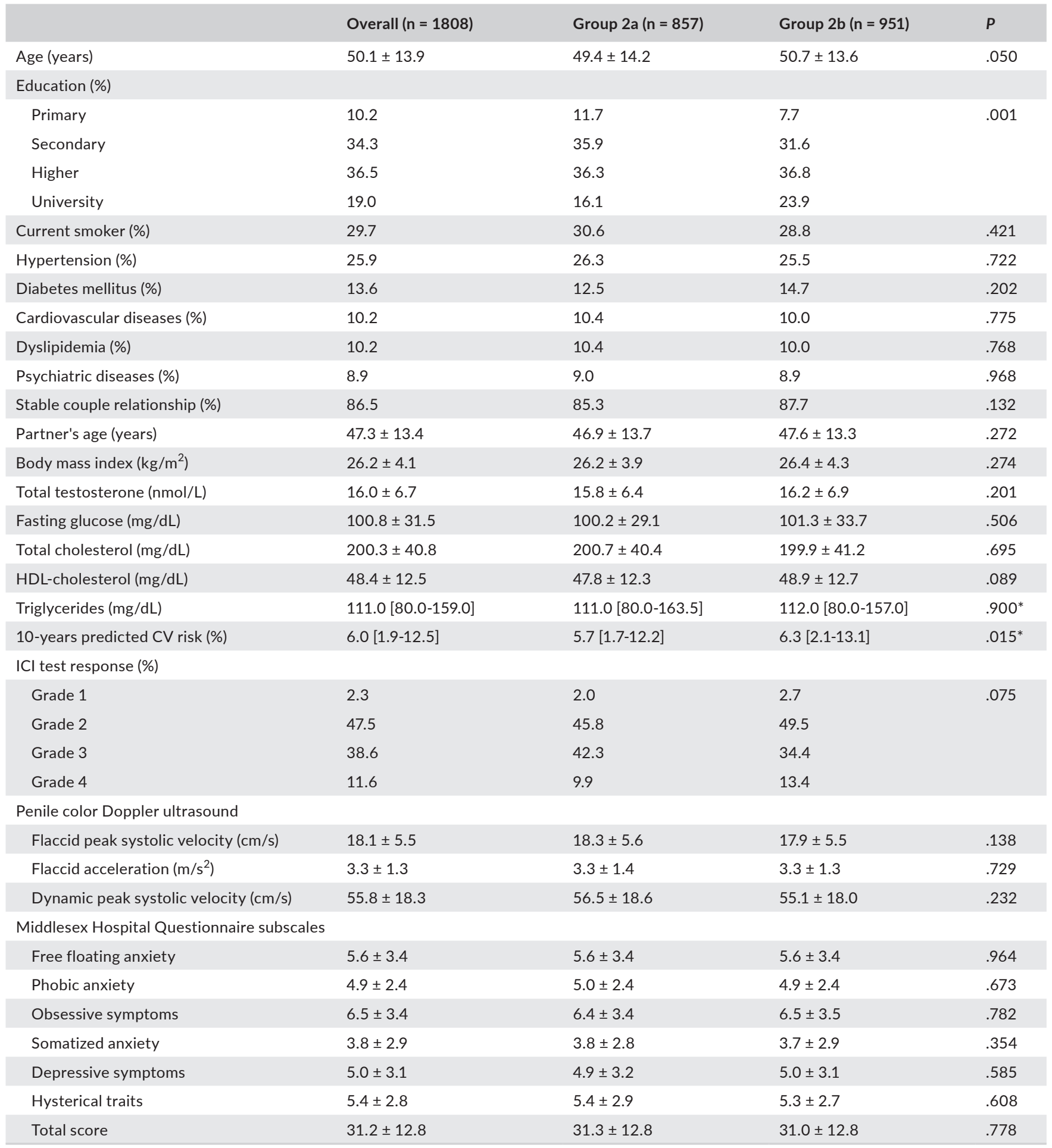

Note: Continuous variables are reported as mean \pm standard deviation when normally distributed or median [interquartile range] when non-normally distributed, categorical variables are reported as percentage. $p$ values refer to the comparison between group $2 \mathrm{a}$ (referent) and group $2 \mathrm{~b}$. Student's $t$ test and chi-square test were used for the comparison in continuous and categorical variables, respectively.

Abbreviations: $\mathrm{ICl}$, intracavernous injection; $\mathrm{HDL}$, high-density lipoprotein; $\mathrm{CV}$, cardiovascular.

${ }^{*} \log _{10}$ transformed values have been used for performing the $t$ test.

collection of the data. Based on this design, an a priori evaluation of the sample size needed was not performed. Moreover, the clinical procedures considered in this study were not originally designed to detect the physician gender effect on the andrological evaluation but they were rather part of the routine clinical practice of the two centers involved. In addition, information on 


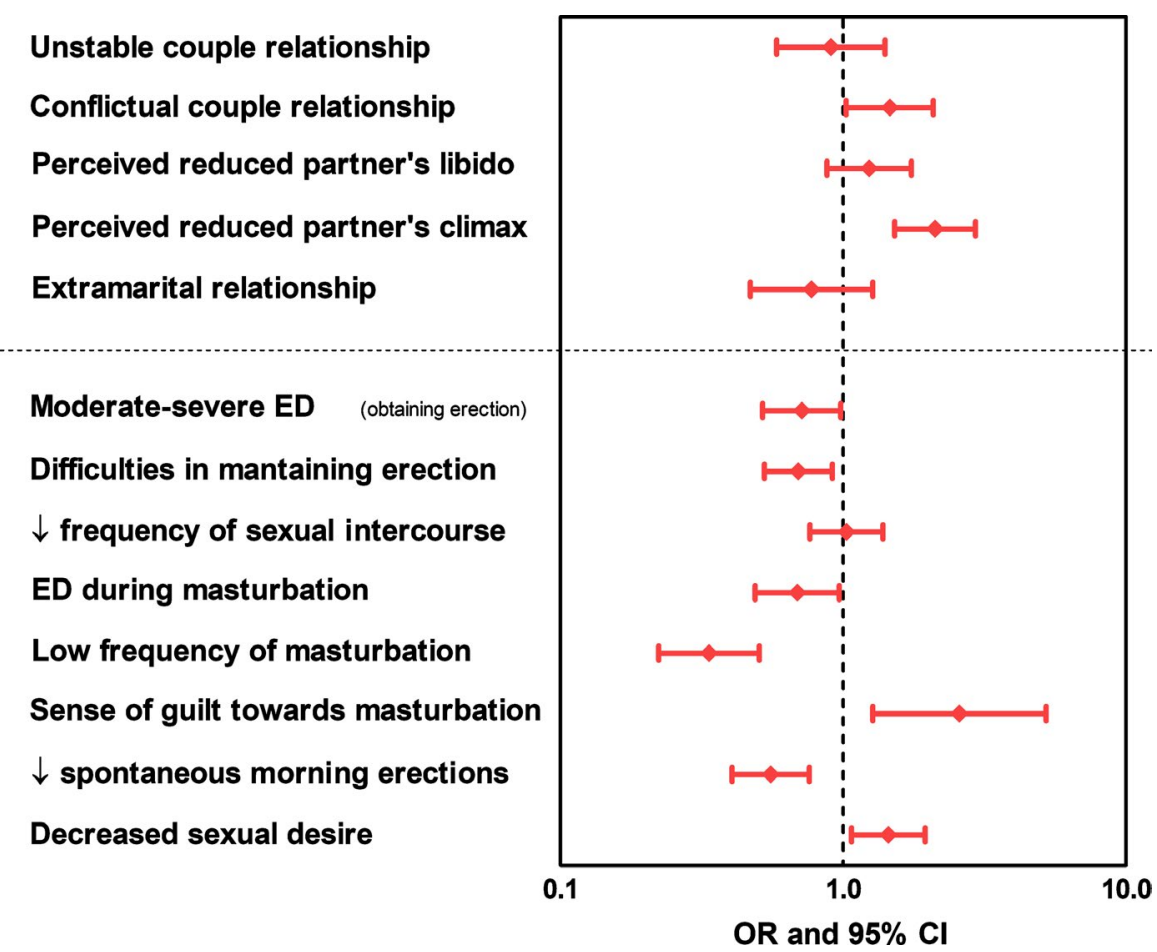

FIGURE 3 Response to questions on couple relationship issues and sexual complaints included in the SIEDY and ANDROTEST structured interviews according to the gender of the interviewing physician in the UNIFI cohort. Data derive from binary logistic regressions using physician gender as the independent variable (male as the referent) and the answers to SIEDY questions as the independent variable. The analyses are adjusted for patient's age, education degree, smoking status, and predicted cardiovascular risk. OR, odds ratio; $\mathrm{Cl}$, confidence interval; $\mathrm{ED}$, erectile dysfunction; SIEDY, structured interview on erectile dysfunction patients' sexual orientation was not evenly available at UNIFI; thus, it was not reported and considered for this study. Finally, the $\mathrm{ICl}$ test and the andrological interview were not replicated on the same patient by a female and a male clinician, limiting the strength of our conclusions. To overcome these limitations, future prospective studies will be designed.

The main strength of this study relies on its novelty. In fact, although evaluated in more generalist medical contexts, the influence of physician gender in a sensitive setting, such as the andrological one, has never been evaluated so far. Another asset is represented by the use of different instruments for the evaluation of the sexual problems, including subjective and objective measurements. The large sample size and the independence of the two cohorts studied represent further strengths.

\section{5 | CONCLUSIONS}

Physician gender affects the results obtained during the diagnostic workup performed for ED. In particular, female physicians capture less severe erectile problems either when the patients subjectively report ED or when ED is assessed by a more objective testing, such as the $\mathrm{ICl}$ test. This result could be explained by the attempt of men to defend their own virility and by a desire-probably unconscious-to minimize in front of doctors of the opposite gender the sexual problem, which is diverted to a sort of partner responsibility. On the other hand, male physicians seem to elicit a more stressful response, which leads to the occurrence of a worse response to the $\mathrm{ICl}$ of $\mathrm{PGE}_{1}$.

Although these results must be confirmed by specifically designed studies, they denote that the assessment of ED severity is different when performed by males of females. Which of the two genders is able to capture the response closest to the true situation is beyond the potential of the present study. However, physicians should be aware of the possible discrepancy in the results. It is likely that the most complete clinical picture can be drawn by a combined evaluation of male and female physicians that, using different skills, can notice different aspects, thus helping to obtain an overall evaluation of the patients complaining about ED.

\section{CONFLICT OF INTEREST}

The authors have no conflict of interest to disclose.

\section{AUTHORS' CONTRIBUTIONS}

All authors participated in the writing, editing, creation, and approval of this paper. GR conceived the study, analyzed the data, provided data interpretation, and wrote the manuscript. SC, AC, SDV, ARMG, and GS collected the data and assisted in writing. MS and MM provided data interpretation and assisted in writing. DS conceived the study, analyzed the data, provided data interpretation, and wrote the manuscript. The corresponding author attests that all listed authors meet authorship criteria and that no others meeting the criteria have been omitted.

\section{ORCID}

Mario Maggi (iD https://orcid.org/0000-0003-3267-4221

Daniele Santi (iD https://orcid.org/0000-0001-6607-7105

\section{REFERENCES}

1. Corona G, Lee DM, Forti G, et al. Age-related changes in general and sexual health in middle-aged and older men: results from the European Male Ageing Study (EMAS). J Sex Med. 2010;7:1362-1380. 
2. Laumann EO, Paik A, Rosen RC. Sexual dysfunction in the United States: prevalence and predictors. JAMA. 1999;281:537-544.

3. Kubin M, Wagner G, Fugl-Meyer AR. Epidemiology of erectile dysfunction. Int J Impot Res. 2003;15:63-71.

4. Perelman M, Shabsigh R, Seftel A, Althof S, Lockhart D. Attitudes of men with erectile dysfunction: a cross-national survey. J Sex Med. 2005;2:397-406.

5. Burnett AL, Nehra A, Breau RH, et al. Erectile dysfunction: AUA guideline. J Urol. 2018;200:633-641.

6. Roter DL, Hall JA, Aoki Y. Physician gender effects in medical communication: a meta-analytic review. JAMA. 2002;288:756-764.

7. Rosen RC, Cappelleri JC, Smith MD, Lipsky J, Peña BM. Development and evaluation of an abridged, 5-item version of the International Index of Erectile Function (IIEF-5) as a diagnostic tool for erectile dysfunction. Int J Impot Res. 1999;11:319-326.

8. Belew D, Klaassen Z, Lewis RW. Intracavernosal injection for the diagnosis, evaluation, and treatment of erectile dysfunction: a review. Sex Med Rev. 2015;3:11-23.

9. Goldstein I, Auerbach S, Padma-Nathan H, Rajfer J, Fitch W, Schmitt L. Axial penile rigidity as primary efficacy outcome during multi-institutional in-office dose titration clinical trials with alprostadil alfadex in patients with erectile dysfunction. Alprostadil Alfadex Study Group. Int J Impot Res. 2000;12:205-211.

10. Petrone L, Mannucci E, Corona G, et al. Structured interview on erectile dysfunction (SIEDY): a new, multidimensional instrument for quantification of pathogenetic issues on erectile dysfunction. Int J Impot Res. 2003;15:210-220.

11. Corona G, Mannucci E, Petrone L, et al. ANDROTEST: a structured interview for the screening of hypogonadism in patients with sexual dysfunction. J Sex Med. 2006;3:706-715.

12. Palmieri L, Panico S, Vanuzzo D, et al. [Evaluation of the global cardiovascular absolute risk: the Progetto CUORE individual score]. Ann Ist Super Sanita. 2004;40:393-399.

13. Rastrelli G, Corona G, Fisher AD, Silverii A, Mannucci E, Maggi M. Two unconventional risk factors for major adverse cardiovascular events in subjects with sexual dysfunction: low education and reported partner's hypoactive sexual desire in comparison with conventional risk factors. J Sex Med. 2012;9:3227-3238.

14. Crown S, Crisp AH. A short clinical diagnostic self-rating scale for psychoneurotic patients. The Middlesex Hospital Questionnaire (M.H.Q.). Br J Psychiatry. 1966;112:917-923.

15. Song SH, Kim DS, Yoon TK, Hong JY, Shim SH. Sexual function and stress level of male partners of infertile couples during the fertile period. BJU Int. 2016;117:173-176.

16. Lotti F, Maggi M. Sexual dysfunction and male infertility. Nat Rev Urol. 2018;15:287-307.

17. Penzias A, Bendikson K, Butts S, et al. Diagnostic evaluation of sexual dysfunction in the male partner in the setting of infertility: a committee opinion. Fertility Sterility 2018;110(5):833-837.

18. Boddi V, Fisher AD, Maseroli E, et al. Lack of sexual privacy affects psychological and marital domains of male sexual dysfunction. J Sex Med. 2014;11:431-438.

19. Beglinger LJ, Gaydos B, Tangphao-Daniels O, et al. Practice effects and the use of alternate forms in serial neuropsychological testing. Arch Clin Neuropsychol. 2005;20:517-529.

20. Ivnik RJ, Smith GE, Lucas JA, et al. Testing normal older people three or four times at 1- to 2-year intervals: defining normal variance. Neuropsychology. 1999;13:121-127.

21. Hojat M, Gonnella JS, Nasca TJ, Mangione S, Vergare M, Magee M. Physician empathy: definition, components, measurement, and relationship to gender and specialty. Am J Psychiatry. 2002;159:1563-1569.

How to cite this article: Rastrelli G, Cipriani S, Craparo A, et al. The physician's gender influences the results of the diagnostic workup for erectile dysfunction. Andrology. 2020;00:1-9. https://doi.org/10.1111/andr.12759 